\title{
Apnea, CTCAE
}

National Cancer Institute

\section{Source}

National Cancer Institute. Apnea, CT CAE. NCI Thesaurus. Code C55340.

A disorder characterized by cessation of breathing. 